\title{
Care experiences of young people with eating disorders and their parents: qualitative study
}

Oana Mitrofan, Hristina Petkova, Astrid Janssens, Jonathan Kelly, Eve Edwards, Dasha Nicholls, Fiona McNicholas, Mima Simic, Ivan Eisler, Tamsin Ford and Sarah Byford

\section{Background}

Perspectives of young people with eating disorders and their parents on helpful aspects of care should be incorporated into evidence-based practice and service design, but data are limited.

\section{Aims}

To explore patient and parent perspectives on positive and negative aspects of care for young people with eating disorders.

\section{Method}

Six online focus groups with 19 young people aged 16-25 years with existing or past eating disorders and 11 parents.

\section{Results}

Thematic analysis identified three key themes: the need to (a) shift from a weight-focused to a more holistic, individualised and consistent care approach, with a better balance in targeting psychological and physical problems from an early stage; (b) improve professionals' knowledge and attitude towards patients and their families at all levels of care from primary to 'truly specialist'; (c) enhance peer and family support.

\section{Conclusions}

Young people and parents identified an array of limitations in approaches to care for young people with eating disorders and raised the need for change, particularly a move away from a primarily weight-focused treatment and a stronger emphasis on psychological needs and individualised care.

\section{Declaration of interest}

None.

\section{Keywords}

Qualitative research; anorexia nervosa; bulimia nervosa; carers; eating disorders NOS.

\section{Copyright and usage}

(C) The Royal College of Psychiatrists 2019. This is an Open Access article, distributed under the terms of the Creative Commons Attribution-NonCommercial-NoDerivatives licence (http://creativecommons.org/licenses/by-nc-nd/4.0/), which permits noncommercial re-use, distribution, and reproduction in any medium, provided the original work is unaltered and is properly cited. The written permission of Cambridge University Press must be obtained for commercial re-use or in order to create a derivative work.
Eating disorders are serious conditions of increasing prevalence among young people. ${ }^{1}$ In the UK, out-patient treatment ${ }^{2}$ was historically delivered in generic child and adolescent mental health services (CAMHS) or highly specialised eating disorder services, with significant regional variation in provision. ${ }^{3}$ Although there is growing evidence about the efficacy of particular treatments, ${ }^{2}$ our knowledge about the impact of different clinical settings on treatment outcomes is limited. Studies suggested that specialist service provision may lead to better case identification, greater consistency of care and be more cost-effective, ${ }^{4-7}$ but the data are limited. In England, there has been recent investment in specialist community eating disorder services for young people in all regions, ${ }^{8}$ the impact of which is unknown. These developments are contemporaneous with increasing emphasis on patient-led recovery approaches to eating disorders as well as patient and carer participation in service design, for which data on patient and carer perspectives are important.

Qualitative research can facilitate a better understanding of what patients perceive as optimum care. ${ }^{9}$ In the field of eating disorders such understanding mostly comes from qualitative studies in adults, with research on adolescents' perspectives of treatment and recovery more recently emerging. Previously identified themes highlighted the role of family, peers and professionals, family therapy, the in-patient setting, emphasis on physical versus psychological aspects and conceptualisation of recovery among adolescents with anorexia nervosa. ${ }^{10}$ Most previous qualitative research has focused on anorexia nervosa rather than broader eating disorder diagnoses. ${ }^{11}$ However, current service provision does not typically provide distinctive care pathways or services for different types of eating disorders. Research also focused on experiences of specific treatment settings, particularly in-patient care and parallel exploration of young people's and parents' perspectives is limited. Greater satisfaction with treatment and more positive experiences of family therapy have been reported by parents compared with adolescents with anorexia nervosa. ${ }^{12}$ Our study aimed to explore young people's and parents' experiences of care for eating disorders, both positive and negative, across various treatment settings and the ways care could be improved by using thematic analysis. We hypothesised that, despite the ego-syntonic features often encountered in eating disorders, young people want good care towards recovery, and their views would be similar to those of parents on what constitutes good healthcare.

\section{Method}

\section{Participants}

A purposive, non-probability sampling method was used to identify individuals who were likely to have experience of a range of different eating disorder service provisions. Young people aged 16-25 years who had an ongoing or past eating disorder and had contact with healthcare services in relation to their eating disorder, and parents of young people in the same situation, were recruited through Beat using an online advertisement. Beat is the UK national eating disorder charity, which has supported extensive research in this field by facilitating recruitment (http://www.beateatingdisorders.org.uk). Attention was drawn to the advertisement via Beat's email database and its Facebook and Twitter profiles. Responders to the study advertisement were provided with further information about the study via email. Recruitment continued until saturation of themes was reached (i.e. the point at which no new ideas emerge 
from additional data collection). ${ }^{13}$ All participants gave written consent to take part via email. Ethical approval was granted by the University of Exeter Medical School Research Ethics Committee (REC REF Apr15/B/062).

\section{Data collection}

Participants completed a baseline questionnaire covering demographic information, details of healthcare services used in relation to their eating disorder, or, in the case of parent participants, those of their child's eating disorder. Focus groups for young people and parents were facilitated separately. In order to provide a balance of experience of different service provision in each group (out-patient and in-patient, generic and specialist, child and adult services), we drew on the baseline questionnaire data on type of healthcare services they had used for eating disorders to allocate participants, as much as possible, given the response rate and participant availability. Each of the four online focus groups with young people included a mixture of younger and older participants (i.e. below and above the mean age for the sample), also of mixed diagnosis and treatment status (except for one group where by chance all participants had anorexia nervosa and were no longer receiving treatment). Each parental group included a participating father; one group included parents of a child with anorexia nervosa and mixed treatment status, and the second group included parents reporting more than one diagnostic category and whose children were no longer in treatment for their eating disorders.

Each focus group was convened as a synchronous 'chatroom' for a maximum of seven individuals in the Chat Blazer software (www. chatblazer.com). Each participant was provided with a unique, non-identifying username and password. Participants had no access to others' personal information except for their chosen usernames. Each group was run by an experienced Beat moderator and a group facilitator from the research team. The facilitator led the group by introducing the topics of the semi-structured guide, which included open questions and prompts. The topics were identified through a review of the existing literature. ${ }^{10,14,15}$ and from the authors' clinical experience and covered the following areas: overall experience of services including accessibility, flexibility, medical assistance, professional encounters, key professional qualities/skills, individual and family support and important treatments; helpful aspects of care; unhelpful aspects of care, potential changes to these and desired impact of change; views on specialist services versus generic CAMHS; views on community versus in-patient services; views on age division within services and experience of adult services; and suggestions for service improvement (see Supplementary Material, available at https://doi.org/10.1192/bjo.2018.78).

The moderator was responsible for setting the 'ground rules', monitoring for any sensitive issues and rejecting any unsuitable comments prior to them being shared. Each participant typed their answers, which, after being approved by the moderator, were displayed on screen for others to read and respond to. Each group had a chat supervisor (member of the research team) who provided support to distressed participants through private online communication (separate closed chatroom). This included the recommendation to contact a healthcare professional such as their general practitioner (GP) (the research team did not have participants' consent to make contact directly on their behalf) and signposting to other support services (only one participant required this). Each group lasted between 60 and $90 \mathrm{~min}$. All participants were invited to comment on the transcript of the group they participated in and on a summary of findings.

\section{Data analysis}

Focus group transcripts were generated automatically by participants' typed responses (mean word count 6043, s.d. $=1351.8$, range 3587-7258 words). All transcripts were analysed in NVivo software (http://www.qsrinternational.com/nvivo/nvivo-products) using thematic analysis. ${ }^{16}$ This involved a detailed reading and rereading of the transcripts, identifying and labelling codes in each transcript, arranging the codes into themes and summarising the themes. This process was carried out iteratively with the team of researchers moving back and forth between transcripts and emerging themes. In order to address potential preconceptions of the main rater, three transcripts of two groups with young people and one with parents were independently coded and extracted themes were subsequently compared and discussed until full agreement on final themes was reached.

\section{Results}

Characteristics of the young people who participated in the study are described in Table 1. A total of 19 females aged 16-25 years (mean age 20.7, s.d. $=3.3$ ) took part in four online focus groups. Only one participant was from an ethnic minority. Nearly twothirds had or were recovering from anorexia nervosa and the remainder had or were recovering from bulimia nervosa, 'other/ atypical eating disorders' or a combination of these. Mean illness duration was 6 years (s.d. $=3.6$, range 15 months to 13 years).

Eleven parents took part in two online focus groups. Most were mothers $(n=9)$, none were from an ethnic minority and the majority had a daughter $(n=9)$ rather than a son $(n=2)$ with an eating disorder, mostly anorexia nervosa. One participant reported a combination of anorexia nervosa and binge-eating disorder (Table 2). Mean age of their child at the point of diagnosis was 14.7 years (s.d. $=2.1$, range 11-17). Mean duration of their child's illness was 5 years (s.d. $=4.1$, range 12 months to 15 years). As a result of the anonymity assured by our protocol, we were not able to establish the overlap between the young people and parent samples (although three participants disclosed this).

Most young people had used a mixture of healthcare services. Use of private healthcare was scarce (young people $16 \%, n=3$; parents $18 \%, n=2$ ). For both samples, nearly two-thirds of young people were no longer in treatment (young people 63\%, $n=12$; parents $64 \%, n=7$ ).

Three main themes emerged from participating young people's and parents' accounts of their experiences of care. Each main theme and its subthemes are discussed in turn and illustrated by participants' first-hand quotations. The source of each quotation is indicated by the participant's study ID number (YP,young person; PA, parent). Three secondary themes and supporting quotes are presented in Table 3.

\section{Early, holistic, individualised and consistent care}

All participants' accounts (young people and parents) suggest an imbalance between physical and psychological aspects of care. Most participants described good experiences of the care addressing physical health needs, but reported that there was too much focus on patient's weight while neglecting psychological aspects and more personalised, life-long skills.

\section{Early intervention}

Participants viewed referral to services and admission for treatment as largely dictated by the patient's weight, setting a threshold that appeared to promote weight loss as a means of accessing support. Delaying intervention as the patient was 'not ill enough' was seen as likely to hinder recovery, as opposed to early consideration of relevant emotional and behavioural symptoms: 


\begin{tabular}{|c|c|c|c|c|c|}
\hline Study ID & Age, years & Diagnosis & $\begin{array}{l}\text { Total illness } \\
\text { duration, years }\end{array}$ & $\begin{array}{l}\text { Treatment } \\
\text { status }\end{array}$ & Healthcare services and interventions used \\
\hline YP1 & 21 & Anorexia nervosa & 6 & Ongoing & $\begin{array}{l}\text { Out-patient, in-patient, day-patient, paediatric, CAMHS, } \\
\text { AMHS, CYP-EDS, AEDS }\end{array}$ \\
\hline YP2 & 24 & Anorexia nervosa and bulimia nervosa & 13 & Ended & Out-patient, hypnotherapy, psychotherapy, dietetics \\
\hline YP3 & 16 & Anorexia nervosa & 1.25 & Ongoing & Out-patient, in-patient, day-patient, paediatric, CAMHS \\
\hline YP4 & 24 & Anorexia nervosa & 8 & Ongoing & Out-patient, day-patient, AMHS, AEDS (also private services) \\
\hline YP5 & 17 & Anorexia nervosa & 3 & Ended & Out-patient, CYP-EDS, AEDS (also private services) \\
\hline YP6 & 25 & Anorexia nervosa & 8 & Ended & Out-patient, CAMHS, AMHS, AEDS \\
\hline YP7 & 20 & Bulimia nervosa & 4 & Ended & Out-patient, CAMHS, AMHS, CYP-EDS, AEDS \\
\hline YP8 & 24 & Other/atypical eating disorder & 10 & Ended & Individual and group psychotherapy (CBT, mindfulness) \\
\hline YP9 & 20 & Anorexia nervosa & 4 & Ongoing & Out-patient, AMHS, AEDS, counselling (university) \\
\hline YP10 & 25 & Other/atypical eating disorder & 12 & Ended & Out-patient, in-patient, CAMHS, AMHS, CYP-EDS \\
\hline YP11 & 19 & Anorexia nervosa & 3.25 & Ongoing & Out-patient \\
\hline YP12 & $16+^{a}$ & Anorexia nervosa and bulimia nervosa & 7 & Ended & Out-patient, in-patient, day-patient, CAMHS, AMHS \\
\hline YP13 & 22 & Anorexia nervosa & 3 & Ended & Out-patient, AMHS \\
\hline YP14 & 16 & Anorexia nervosa & 1.25 & Ended & Out-patient, CAMHS \\
\hline YP15 & 18 & Anorexia nervosa & 2 & Ended & Out-patient, in-patient, day-patient, paediatric, CAMHS \\
\hline YP16 & 24 & Anorexia nervosa and bulimia nervosa & 9 & Ended & Out-patient, CAMHS, AMHS (also private services) \\
\hline YP17 & 18 & Anorexia nervosa & 5 & Ongoing & Out-patient, AMHS, AEDS \\
\hline YP18 & 24 & Anorexia nervosa & 10 & Ongoing & Out-patient, CAMHS, AMHS, CYP-EDS, AEDS \\
\hline YP19 & 16 & $\begin{array}{l}\text { Anorexia nervosa, bulimia nervosa } \\
\text { and other/atypical eating disorder }\end{array}$ & 4 & Ended & Out-patient, in-patient, day-patient, CAMHS \\
\hline
\end{tabular}

'...specialist services are simply brought in too late. They're supposed to catch you, but often you have to fall quite a way to get there.' (YP9)

'One of the main challenges is getting help early enough. There is too much attention paid to weight loss and not enough to the behaviour patterns and so they are dangerously low in weight before you get referred...It is the strange behaviour around food and rituals that indicate a problem. They may not be dangerously low in weight at this stage but far more retrievable.' (PA9)

\section{'Seeing the whole person'}

Most participants experienced professional help as being targeted towards reaching a 'minimum healthy weight' with limited psychological input. This often led to deterioration and relapse as their underlying difficulties of how to 'deal with emotion and lack of control' persisted. They advocated a holistic approach aiming towards 'recovery in body and mind':

'I recovered physically and got back to a healthy weight, but then with that recovery comes a huge psychological struggle and thus high risk of relapse, which certainly wasn't addressed at the time...' (YP3)

'Really what you need is someone who sees the whole person the link between the medical and psychological condition and treats both together.' (PA1)

Many young people described upsetting sessions that revolved around 'the number on the scale' and frequent weighing 'like a pig at the fair', while their thoughts and emotions were 'brushed off. One recalled:

'...I was feeling really positive about my recovery after reading a book about someone who had recovered and "seeing the

\begin{tabular}{|c|c|c|c|c|c|}
\hline $\begin{array}{l}\text { Study } \\
\text { ID }\end{array}$ & $\begin{array}{l}\text { Young person's age } \\
\text { at diagnosis, years }\end{array}$ & $\begin{array}{l}\text { Young person's } \\
\text { diagnosis }\end{array}$ & $\begin{array}{l}\text { Total duration of young } \\
\text { person's illness, years }\end{array}$ & $\begin{array}{l}\text { Young person's } \\
\text { treatment status }\end{array}$ & Healthcare services and interventions used \\
\hline PA1 & 17 & Anorexia nervosa & 2 & Ended & CAMHS \\
\hline PA2 & 11 & Anorexia nervosa & 3.5 & Ongoing & $\begin{array}{l}\text { Out-patient, in-patient, day-patient, paediatric, } \\
\text { CAMHS, CYP-EDS }\end{array}$ \\
\hline PA3 & 16 & Anorexia nervosa & 3.6 & Ongoing & Out-patient, in-patient (also private services) \\
\hline PA4 & 11 & Anorexia nervosa & 1 & Ongoing & $\begin{array}{l}\text { Out-patient, in-patient, day-patient, paediatric, } \\
\text { CAMHS, CYP-EDS (also private services) }\end{array}$ \\
\hline PA5 & 16 & Anorexia nervosa & 2.8 & Ongoing & Out-patient, CYP-EDS, AEDS \\
\hline PA6 & 17 & Anorexia nervosa & 2 & Ended & Out-patient \\
\hline PA7 & 14 & $\begin{array}{l}\text { Anorexia nervosa and } \\
\text { bulimia nervosa }\end{array}$ & 9 & Ended & $\begin{array}{l}\text { Out-patient, in-patient, day-patient, CAMHS, } \\
\text { AMHS, CYP-EDS, AEDS (also private services) }\end{array}$ \\
\hline PA8 & 16 & Anorexia nervosa & 4.1 & Ended & $\begin{array}{l}\text { Out-patient, in-patient, day-patient, paediatric, } \\
\text { CAMHS, AMHS, CYP-EDS }\end{array}$ \\
\hline PA9 & 16 & Anorexia nervosa & 3 & Ended & Out-patient, AMHS \\
\hline PA10 & 14 & $\begin{array}{l}\text { Anorexia nervosa and } \\
\text { binge-eating disorder }\end{array}$ & 15 & Ended & $\begin{array}{l}\text { Out-patient, in-patient, CAMHS, AMHS, CYP-EDS, } \\
\text { AEDS }\end{array}$ \\
\hline PA11 & 14 & Anorexia nervosa & 8 & Ended & Out-patient, paediatric, CAMHS, AMHS, dietetics \\
\hline
\end{tabular}




\section{Access to care}

The 'postcode lottery' (geographical variation in type and quality of care)

Resources and waiting lists

Out-of-hours care

Flexibility

Generic psychotherapeutic skills

Professional communication

'Joined up thinking'

Information sharing and follow-up '...it's just very difficult to comprehend if you haven't experienced it day in day out. This is maybe why there's value in groups? But again, very much a postcode lottery - there isn't one anywhere near me.' (YP9)

'We live in a rural area I feel the service was understaffed and poorly trained and supported. We withdrew from treatment as it was causing more harm...I know of several specialised units based in the larger towns around us but we did not have access to them.' (PA9)

'...I was put on a 6-month waiting list for counselling, and within 3 months was in A\&E in critical condition. Unless you are critically ill, it is very difficult to access any form of service.' (YP15) '...CAMHS have such long waiting lists and they're in a rush to get you out of there....this in turn led to a relapse.' (YP7)

'...there were many crisis points which of course were out of hours and it was very difficult to get the help we needed. CAMHS was helpful overall - just the crisis points were what nearly finished me.' (PA1)

'...they weren't/aren't very flexible with the time slots available which means missing important aspects of school and my parents find it hard to fit appointments in with work.' (YP19)

'I can't fault the staff I have encountered... the qualities that are most important to me are that they form a really good relationship and are very kind and caring. They should establish complete trust with the patient, in such a way that you feel comfortable telling them anything... Also being funny and happy is a great help when you're feeling very low yourself!' (YP3)

'For me the key thing in any treatment she was given was to be listened to and not just be treated as someone with anorexia. She received this from only 4 professionals out of the 14 or so she had dealings with.'(PA11)

'My number one priority would be joined up thinking - GPS, A\&E staff, general mental health services, adult and CAMHS services talking to each other.' (PA10)

'... registering as a temporary patient and seeing someone who has no idea of your medical records etc. is distressing and anxiety provoking and the temptation is to slip off the radar - I don't know if there could be some form of correspondence between Uni and home GPS?' (YP9)

A\&E, accident and emergency department; CAMHS, child and adolescent mental health services; GP, general practitioner.

light" a bit but when I arrived at my session, stepped on the scales and had lost weight the whole session turned to be about food. I never even got to mention the book and how it made me feel.' (YP6)

The interplay between a weight-driven approach to treatment and the 'competitive nature' of eating disorders could create a vicious cycle. One participant felt she was 'taken more seriously' the lower her weight was, which 'fed the illness itself as her eating disorder would see this as being 'successful'. Another felt she needed to make herself worse to ensure support:

'I spoke to my psychiatrist once I got to a healthy weight and she said there isn't much they can do if I'm not ill which really upset me...Just focus more on the emotional side...I still don't really know how to get better. I wish she hadn't said there was nothing she could do because I wasn't ill physically because that makes you think you need to make yourself ill to get help which shouldn't be the case!' (YP14)

Young people talked about the complex nature of their condition that 'consumes every single aspect' of their lives. They felt that treatment should address 'how to live long term' and ways of 'keeping the eating disorder at bay':

'....anorexics think about their condition every second of the day...even in my dreams I still have the condition... Recovery shouldn't be just meal times and weight focused.' (YP12)

Some parents highlighted the absence of the recovery topic in professional contacts and their struggles to find 'actual evidence that people could recover'. For others, the recovery message was conveyed in unhelpful ways:

'Our initial treatment didn't promise "recovery" but...they did...stress that full recovery was possible...It just seemed that they sort of blamed the parents before 18 and the patient after 18 if that didn't happen!' (PA10)

\section{Individualised approach}

Many participants experienced a 'one size fits all' approach, where professionals were 'treating the condition not the person' and evidence-based interventions were applied with 'little understanding of individuals recovering differently'. They recommended a more personalised approach that would help them find their 'own positive reasons to recover':

'I disagree with the homogeneity of treatment methods. Where I am at the moment, they are very good at tailoring recovery to the individuals' needs... my therapist... has a way of putting my recovery in my hands.' (YP1)

\section{Consistency and continuity}

Several participants experienced frequent, disruptive changes in professionals and 're-telling the same story' at each new clinical encounter:

'...building up relationships with individual counsellors, etc. takes time, and having to cut and change as the services chop and change has been quite unsettling.' (YP17)

A key issue was the gap in treatment provision when young people made the transition from child and adolescent to adult services, which often triggered clinical deterioration:

'CAMHS gave up on me when I was about 17 and 2 months and I couldn't start adult treatment until 18 - that gap was when I made the biggest decline.' (YP6)

This transition takes place 'right in the middle of the struggle years' and the disconnection between services was described as an 'artificial divide'. Suggested alternatives were changing the age 
boundary to 25 years, a flexible approach 'dictated by needs rather than age' or an 'integrated 8-80 specialist eating disorder team'.

\section{Knowledge of eating disorders at all levels of care}

A salient issue in both young people' and parents' accounts concerned the insufficient knowledge of the nature and clinical management of eating disorders among various professionals working across all levels of care.

\section{Knowledge at primary care level}

Primary care practitioners have a gatekeeping role, crucial for early identification and referral. Although willing to help, they often lacked knowledge in the identification of eating disorders and when and where to refer:

'The general opinion of the GP when I first visited was to go away for a month and come back if there was still a problem. For an eating disorder, I think this is very poor considering how much weight you can lose in a month...' (YP17)

'If I were to express any misgivings, it will be about the time it took to get a referral from her GP to CAMHS...there is a huge variety of awareness on eating disorders among GPs, some of the responses given to my daughter were appalling and wouldn't even have registered with the Ladybird book on eating disorders.' (PA8)

\section{'True' specialist services}

Many participants experienced 'an extreme lack of experience and knowledge in eating disorders' among various professionals working in general hospitals, emergency services, generic mental health and more specialist eating disorder services:

'...the NHS mental health service I was with had seemed to take people who had jobs as counsellors, physios, dieticians...they thought that they would be helpful but because they are not specialists it made it ten times worse.' (YP5)

'...you get referred for "more specialist" advice to someone who knows a LOT less about the subject than the nurses doing the referring.' (PA10)

Professionals who 'know their stuff about eating disorders' and have 'real hands-on experience of eating disorders' were 'invaluable'. These skills were not necessarily linked to service type: specialist eating disorder services were seen as beneficial as long as they were 'truly specialist not just in name only':

'We reacted best to people who had experience of eating disorders, who calmly said yes, we will help you get out of this.' (PA4)

Professionals' knowledge appears key in avoiding inconsistent or incorrect information being given to families. Several participants recalled feeling 'bewildered' and having to make 'the first move in every direction'. Many participants highlighted the need for early psychoeducation including clear information about standard and crisis care:

'I think giving families information around the causes of eating disorders and also how to act/miss a crisis. How to talk about things and strategies to plan for stressful times.' (YP16)

'There is no clear route to treatment in the early weeks. CAMHS was unable/unwilling to lay out the possible treatment pathways, so every family would start the long education process right from scratch.' (PA4)

\section{Professionals' attitude}

Many participants described professionals who were 'far too judgemental' and made 'devaluing' comments, that hindered help- seeking and therapeutic engagement. They sometimes felt openly criticised for 'misbehaving', 'making a fuss' and 'choosing a career' of having an eating disorder. Parents felt blamed for their child's condition and their 'inappropriate use of resources' when seeking help:

'... personal treatment can make a big impact...Even just sort of a helping hand to doctors to sometimes be a bit more sensitive with the stuff they say, for instance comments regarding "superficial self-harm" or that a weight loss/weight gain isn't "serious" just ways of phrasing stuff that can be quite triggering.' (YP18)

'I do think that many clinicians (not necessarily eating disorder specialists, we haven't had this from them) genuinely believe that parents cause eating disorders.' (PA10)

Professionals' attitude was linked to their misunderstanding of eating disorders, inexperience, focus on patient's weight and tendency to compare the patient to others with a similar condition or to healthy individuals:

'...when eating snacks my psychiatrist would talk non-stop about the calories and how she was eating more than me and had already finished hers...not helpful!' (YP9)

\section{Peer and family support}

Talking to someone with a similar experience seemed vital as it gave participants a better understanding of eating disorders, motivation and hope:

'I did like all the people that were trying to help me, they did their best. I just didn't feel like they ever completely got me. In fact the people who did make me feel that way were often people that had experienced an eating disorder as well.' (YP2)

'A lot of support has come from recovered anorexics telling her the struggle to recover is worth it and to keep going. They have helped her through some of her blackest days.' (PA9)

Peer support was often unavailable locally, contributing to a sense of isolation:

'It's funny they tell you about the amount of people suffering with it but I didn't know anyone.' (YP13)

Parents described a similar need for talking to others with related experience:

'I couldn't have got through without being able to discuss the worst aspects with another mum who'd been through it. Some things you can only talk about with others who've experienced it.' (PA1)

Many participants highlighted the need for young people and parent support groups and respite care. Support for family members would relieve some of the burden so that in turn they can support the patient':

'I think allowing my family to breathe and have a break away from me, maybe a chance to meet others supporting patients would have been helpful...Especially for my brothers.' (YP17) 'We had no family support...The professionals only offer care for a short time. Remember the families support the sufferer the rest of the week. Also it impacts on the whole family.' (PA9)

\section{Discussion}

Participants' experiences of type, availability and quality of care were mixed. Positive experiences often concerned care addressing physical health needs, alongside sporadic reports of treatment 
tailored to individual needs, consistency from keyworkers, a good therapeutic relationship, contact with eating disorder specialists and peer support. Common negative experiences, however, suggest a raft of limitations with service provision and the need for change. It is clear that some participants were not offered or accessing an evidence-based psychological intervention. Identification and clinical management appeared dominated by a young person's weight, linked in some cases to professionals' understanding of eating disorders and service thresholds for referral and treatment. Clinical practice thus seemed to contradict the advice some professionals gave to participating young people to stop thinking about diet and weight.

Participating young people and parents' negative experiences are consistent with the findings of an cross-national (USA, UK) survey in adults with eating disorders highlighting the limited availability and inequity in geographical distribution of services, lack of knowledge of eating disorders among GPs, limited access to care unless severely underweight and long waiting lists in the UK sample. ${ }^{14}$ Qualitative exploration among adult patients portrays recovery from eating disorders as a wider phenomenon that goes beyond weight restoration. ${ }^{17}$ Suggested strategies to address control issues and ambivalence towards treatment in adult patients include consideration of wider psychological issues and a sensitive approach, linked to specialist expertise. ${ }^{18}$ Similarly, issues around priority given to physical over psychological recovery, lack of individualised care and need for sensitivity from healthcare staff were noted in a number of qualitative studies of adolescents' experiences of in-patient treatment (as well as out-patient treatment in one study) for anorexia nervosa. ${ }^{19-24}$ Both a positive and a negative impact of peers on adolescents' recovery from anorexia nervosa in an in-patient context has been described. ${ }^{12,19,20,24,25}$ It is worth noting that almost all of these studies were published more than 10 years ago. Qualitative explorations of parents' experiences of their child's care for eating disorder, also dating back 10 years or more for most studies, highlighted the importance of personalised intervention $^{26}$ and specialist knowledge in eating disorders. ${ }^{12,27}$ Peer support for parents has been supported in the literature, sometimes reported as one of the most helpful aspect of care. ${ }^{27,28}$

The main contributions of our study stem from bringing together the combined experiences of young people and parents of treatment in multiple services, and the emerging emphasis on psychological aspects of eating disorders from very early stages and having appropriately trained professionals working across a wide range of services rather than a single specialist service. Qualitative investigations into the meaning of anorexia nervosa to adolescent and adult patients support psychodynamic and cognitive theories of its connection with the development of individuals' own identity and control systems, with a subsequent impact on their help-seeking behaviour and treatment outcome. ${ }^{29}$

Furthermore, a recent qualitative synthesis into the perspective of recovered adult patients suggested four dimensions of psychological well-being - positive relationships with others, self-acceptance, autonomy and personal growth - and self-adaptability/ resilience as fundamental criteria for eating disorder recovery in addition to symptom remission. ${ }^{30}$ In a study using a multidimensional recovery model, adults with eating disorders placed more emphasis on the combined psychological, emotional and social functioning and evaluation of one's own appearance criteria compared with clinicians. ${ }^{31}$ In line with these findings from the adult literature, our study highlights two important aspects in addressing the psychological well-being criteria for recovery and the development of a 'healthy' identity in young people with eating disorders, according to both patients and parents: an earlier consideration of psychological aspects of these conditions that should start at identification in primary care and referral to specialist treatment, as well as enhanced professionals' knowledge of eating disorders and attitude towards patients and families across all levels of care.

Eating disorder services for children and adolescents in England have received a significant investment, and are undergoing major restructuring, ${ }^{8}$ which should address many of these concerns, in particular timely access to psychological interventions independent of weight status. Our findings support the importance of these changes to improve the quality of patient and parent experience, regardless of the cost-effectiveness arguments. However, these standards are not yet applicable to adult eating disorder services, which remain patchy and underresourced. Eating disorder services in Wales are currently subject to a major review for which this study provides timely evidence.

Gaps in health professionals' ability to recognise and treat eating disorders and the negative attitude that some express towards individuals with eating disorders have been previously highlighted as more prevalent compared with other mental or physical illnesses. ${ }^{32,33}$ Our findings are in line with a recently published report highlighting the poor experience of mental health services often encountered by children and young people in the UK. ${ }^{34}$ Others have reported short comings in service provision and suggested strategies for a more consistent and smooth transition to adult mental health services, tailored to the young person's needs and taking into account other simultaneous life changes. ${ }^{35,36}$

\section{Strengths and limitations}

This study recruited a national sample of young people and parents not bound by setting or treatment group. It used synchronous online discussion (i.e. all focus group members temporally copresent) that has recognised similarity to a traditional, face-toface focus group, ${ }^{37}$ but has the advantage of providing an anonymous online environment. This has previously been identified as preferable by young people when discussing sensitive topics because of its private and less judgemental nature. ${ }^{38}$ The young people's age range ensured access to experiences of both child/adolescent and adult services as well as the transition.

The gender imbalance and preponderance of anorexia nervosa are a likely effect of the means of recruitment and self-reported diagnosis, although it is consistent with anorexia nervosa being the dominant presentation of eating disorders to CAMHS services. The recruitment and data collection methods limited participation to consenting older young people and also meant that individuals with easier access to and familiarity with internet use were more likely to participate. Findings may therefore not pertain to all young people with eating disorders and their carers, particularly younger children, males and those from ethnic minorities, and may not generalise to non-UK healthcare settings. Methodological issues around gender and ethnicity imbalance in this field have been previously reported. ${ }^{19,20,23}$

Our recruitment may have skewed the perspective towards negative experiences. Most participating young people were over 18 years of age at the time of the study, had relatively long illness durations and experienced treatment in multiple services, often in-patient or day services, with likely poor initial response to treatment. More than half of them were no longer receiving treatment at the time of the study. Although potentially allowing for more reflective accounts, our sample characteristics may explain the differences between our findings and those of Roots et al, ${ }^{12}$ which were more positive, particularly regarding specialist services. Their study included adolescents with an average duration of illness of just over 1 year, thus perhaps better representing the patient population in child/adolescent services with relatively short illness duration, good response to out-patient treatment and no need of in-patient care or transfer to adult services. The two 
studies thus provide different, complementary perspectives on treatment experiences and suggest the likelihood of more positive experiences if receiving early, specialist intervention. Our findings do echo other similar studies and, rather than the experiences of a dissatisfied minority, they replicate and add to the existing evidence of shortcomings and needed changes in care provision for young people with eating disorders.

\section{Implications}

There was a strong consensus that treatment should not just focus on weight but also address psychological and relational aspects from an early stage. An individualised treatment approach that addresses physical and psychological recovery in parallel, from an individual's first contact with health services throughout their therapeutic journey, is more likely to lead to full recovery and minimise the risk of relapse. Carefully planned peer support for young people, as well as support for parents and siblings would be highly beneficial. Although such changes in care provision may be challenging for many overstretched services, they seem essential in the long term by preventing delayed intervention and longer illness duration, both well recognised predictors of poor clinical outcome. ${ }^{39}$

The role of professionals' knowledge of eating disorders and treatment pathways was perceived as crucial at all levels of care, from primary to 'truly specialist'. Specialty training, such as general practice and core psychiatry training should provide more opportunities to enhance eating disorder knowledge and understanding of patient and family experience of eating disorders among junior doctors. This should particularly target misconceptions around weight loss as a sole or primary factor in the referral and treatment process.

Improving professionals' knowledge at all levels is clearly key to achieving early diagnosis and intervention, ${ }^{40}$ but equally important is to ensure that treatments have a better balance between the necessary focus on restoring nutrition and physical health and psychological well-being. In England, this has been extensively highlighted in the literature and recently brought forward by the new commissioning guidance for children and young people with eating disorders ${ }^{8}$ and advocacy efforts to increase awareness among GPs of the clinical, particularly psychological, indicators of eating disorders and importance of early referral for specialist assessment. However, these efforts will only be effective where specialist services exist and have the capacity to respond. Further research is needed to assess the potential positive impact of these initiatives. The historical nature of retrospective accounts means that some of the issues raised here may have already been addressed in national guidance and service provision. Nonetheless, qualitative data supporting these changes adds impetus to these priorities.

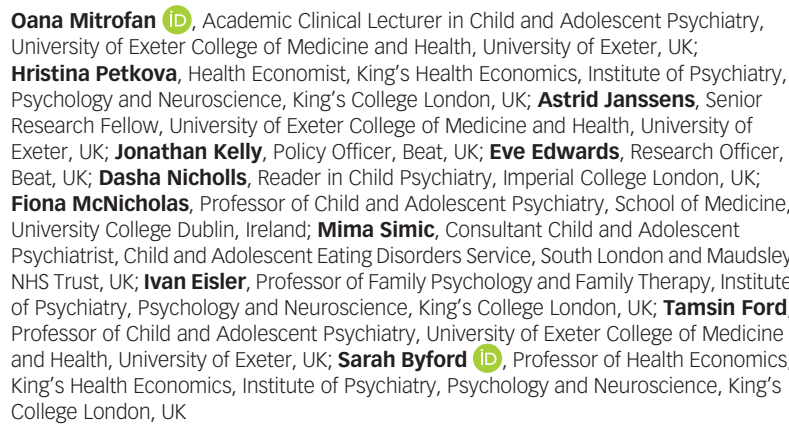

Correspondence: Oana Mitrofan, Room 2.04, University of Exeter College of Medicine and Health, College House, St Luke's Campus, University of Exeter, Exeter EX1 2LU, UK. Email: o.mitrofan@exeter.ac.uk

First received 30 Mar 2018, final revision 17 Sep 2018, accepted 19 Nov 2018

\section{Funding}

O.M. was supported by a NIHR Academic Clinical Lectureship.

\section{Acknowledgements}

We would like to thank all participating young people and parents, Beat, Adrienne Rennie, Amanda Woodrow, Caroline Kalorkoti (Beat Ambassadors), Leoni Randall, Susan Howson and Barbara Barrett who assisted with data collection and manuscript preparation. Work was carried out at the University of Exeter Medical School.

\section{Supplementary material}

Supplementary material is available online at https://doi.org/10.1192/bjo.2018.78.

\section{References}

1 Klump KL, Bulik CM, Kaye WH, Treasure J, Tyson E. Academy for eating disorders position paper: eating disorders are serious mental illnesses. Int J Eat Disord 2009; 42: 97-103.

2 National Institute for Health and Care Excellence. Eating Disorders: Recognition and Treatment. NICE, 2017. (https://www.nice.org.uk/guidance/ng69).

3 Royal College of Psychiatrists. Eating Disorders in the UK: Service Distribution, Service Development and Training. Royal College of Psychiatrists, 2012.

4 Schmidt U, Sharpe H, Bartholdy S, Bonin E-M, Davies H, Easter A, et al. Treatment of anorexia nervosa: a multimethod investigation translating experimental neuroscience into clinical practice. Programme Grants Appl Res 2017; 5: 1-246.

5 Byford S, Barrett B, Roberts C, Clark A, Edwards V, Smethurst N, et al. Economic evaluation of a randomised controlled trial for anorexia nervosa in adolescents. Br J Psychiatry 2007; 191: 436-40.

6 Gowers SG, Clark A, Roberts C, Griffiths A, Edward V, Bryan C, et al. Clinical effectiveness of treatments for anorexia nervosa in adolescents: randomised controlled trial. Br J Psychiatry 2007; 191: 427-35.

7 House J, Schmidt U, Craig M, Landau S, Simic M, Nicholls D, et al. Comparison of specialist and non-specialist care pathways for adolescents with anorexia nervosa and related eating disorders. Int J Eat Disord 2012; 45: 949-56.

8 National Collaborating Centre for Mental Health. Access and Waiting Time Standards for Children and Young People With an Eating Disorder. Commissioning Guide. NCCMH，2015 (https://www.england.nhs.uk/wpcontent/uploads/2015/07/cyp-eating-disorders-access-waiting-time-standardcomm-guid.pdf).

9 Buston K. Adolescents with mental health problems: what do they say about health services? J Adolesc 2002; 25: 231-42.

10 Bezance J, Holliday J. Adolescents with anorexia nervosa have their say: a review of qualitative studies on treatment and recovery from anorexia nervosa. Eur Eat Disord Rev 2013; 21: 352-60.

11 Bell L. What can we learn from consumer studies and qualitative research in the treatment of eating disorders? Eat Weight Disord 2003; 8: 181-7.

12 Roots P, Rowlands L, Gowers SG. User satisfaction with services in a randomised controlled trial of adolescent anorexia nervosa. Eur Eat Disord Rev 2009; 17: 331-7.

13 Bowling A. Research Methods in Health: Investigating Health and Health Services. Open University Press, 2002.

14 Escobar-Koch T, Banker JD, Crow S, Cullis J, Ringwood S, Smith G, et al. Service users' views of eating disorder services: an international comparison. Int J Eat Disord 2010; 43: 549-59.

15 Nishizono-Maher A, Escobar-Koch T, Ringwood S, Banker JD, van Furth E, Schmidt $U$. What are the top five essential features of a high quality eating disorder service? A comparison of the views of US and UK eating disorder sufferers, carers and health professionals. Eur Eat Disord Rev 2011; 19: 411-6.

16 Braun V, Clarke V. Using thematic analysis in psychology. Qual Res Psychol 2006; 3: 77-101.

17 Petterson G, Rosevinge JH. Improvement and recovery from eating disorders: a patient perspective. Eat Disord 2002; 10: 61-71.

18 Reid M, Burr J, Williams S, Hammersley R. Eating disorders patients' views on their disorders and on an outpatient service: a qualitative study. $J$ Health Psychol 2008; 13: 956-60.

19 Colton A, Pistrang N. Adolescents' experiences of inpatient treatment for anorexia nervosa. Eur Eat Disord Rev 2004; 12: 307-16.

20 Offord A, Turner H, Cooper M. Adolescent inpatient treatment for anorexia nervosa: a qualitative study exploring young adults' retrospective views of treatment and discharge. Eur Eat Disord Rev 2006; 14: 377-87. 
21 Tan JO, Hope T, Stewart A. Anorexia nervosa and personal identity: the accounts of patients and their parents. Int J Law Psychiatry 2003; 26: 533-48.

22 Tan JO, Hope T, Stewart A, Fitzpatrick R. Control and compulsory treatment in anorexia nervosa: the views of patients and parents. Int J Law Psychiatry 2003; 26: $627-45$.

23 Tierney S. The individual within a condition: a qualitative study of young people's reflections on being treated for anorexia nervosa. J Am Psychiatr Nurses Assoc 2008; 13: 368-75.

24 Van Ommen J, Meerwijk EL, Kars M, Van Elburg A, Van Meijel B. Effective nursing care of adolescents diagnosed with anorexia: the patient's perspective. $J$ Clin Nurs 2009; 18: 2801-8.

25 Turrell SL, Davis R, Graham H, Weiss I. Adolescents with anorexia nervosa: multiple perspectives of discharge readiness. J Child Adolesc Psychiatr Nurs 2005; 18: $116-26$

26 McMaster R, Beale B, Hillege S, Nagy S. The parent experience of eating disorders: interactions with health professionals. Int J Ment Health Nurs 2004; 13: 67-73.

27 Honey A, Boughtwood D, Clarke S, Halse C, Kohn M, Madden S. Support for parents of children with anorexia: what parents want. Eat Disord 2007; 16: 40-51.

28 Winn S, Perkins S, Murray J, Murphy R, Schmidt U. A qualitative study of the experience of caring for a person with bulimia nervosa. Part 2: carers' needs and experiences of services and other support. Int J Eat Disord 2004; 36: 269-79.

29 Espindola CR, Blay SL. Anorexia nervosa's meaning to patients: a qualitative synthesis. Psychopathology 2009; 42: 69-80.

30 De Vos JA, LaMarre A, Radstaak M, Bijkerk CA, Bohlmeijer ET, Westerhof GJ. Identifying fundemantal criteria for eating disorder recovery: a systematic review and qualitative meta-analysis. J Eat Disord 2017; 5: 34-47.

31 Emanuelli F, Waller G, Jones-Chester M, Ostuzzi R. Recovery from disordered eating: sufferers' and clinicians' perspectives. Eur Eat Disord Rev 2012; 20 363-72.
32 McNicholas F, O'Connor C, O'Hara L, McNamara N. Stigma and treatment of eating disorders in Ireland: healthcare professionals' knowledge and attitudes. Ir J Psychol Med 2016; 33: 21-31

33 Linville D, Brown T, O'Neil M. Medical providers' self-perceived knowledge and skills for working with eating disorders: a national survey. Eat Disord 2012; 20: 1-13.

34 Care Quality Commission. Review of Children and Young People's Mental Health Services. Phase One Report. CQC, 2017 (http://www.cqc.org.uk/publications/themed-work/review-children-young-peoples-mental-health-servicesphase-one-report).

35 McNicholas F, Adamson M, McNamara N, Gavin B, Paul M, Ford T, et al. Who is in the transition gap? Transition from CAMHS to AMHS in the Republic of Ireland. Ir J Psychol Med 2015; 32: 61-9.

36 Hovish K, Weaver T, Islam Z, Paul M, Singh SP. Transition experiences of mental health service users, parents, and professionals in the United Kingdom: a qualitative study. Psychiatr Rehabil J 2012; 35: 251-7.

37 Stewart K, Williams $\mathrm{M}$. Researching online populations: the use of online focus groups for social research. Qual Res 2005; 5: 395-416.

38 Jones R, Sharkey S, Ford T, Emmens T, Hewis E, Smithson J, et al. Online discussion forums for young people who self-harm: user views. Psychiatrist 2011; 35 $364-8$

39 Steinhausen HC. The outcome of anorexia nervosa in the twentieth century. Am J Psychiatry 2002; 159: 1284-93.

40 Ayton A, Ibrahim A. Does UK medical education provide doctors with sufficient skills and knowledge to manage patients with eating disorders safely? Postgrad Med J 2018; 94: 374-80. 